\title{
Economic Incentives to Promote Innovation in Healthcare Delivery
}

\author{
Harold S. Luft PhD
}

Published online: 19 June 2009

(C) The Author(s) 2009. This article is published with open access at Springerlink.com

\begin{abstract}
Economics influences how medical care is delivered, organized, and progresses. Fee-for-service payment encourages delivery of services. Fee-for-individualservice, however, offers no incentives for clinicians to efficiently organize the care their patients need. Global capitation provides such incentives; it works well in highly integrated practices but not for independent practitioners. The failures of utilization management in the 1990s demonstrated the need for a third alternative to better align incentives, such as bundling payment for an episode of care. Building on Medicare's approach to hospital payment, one can define expanded diagnosis-related groups that include all hospital, physician, and other costs during the stay and appropriate preadmission and postdischarge periods. Physicians and hospitals voluntarily forming a new entity (a care delivery team) would receive such bundled payments along with complete flexibility in allocating the funds. Modifications to gainsharing and antikickback rules, as well as reforms to malpractice liability laws, will facilitate the functioning of the care delivery teams. The implicit financial incentives encourage efficient care for the patient; the episode focus will facilitate measuring patient outcomes. Payment can be based on the resources used by those care delivery teams achieving
\end{abstract}

The author certifies that he has no commercial associations (eg, consultancies, stock ownership, equity interest, patent/licensing arrangements, etc) that might pose a conflict of interest in connection with the submitted article.

H. S. Luft (ه)

Palo Alto Medical Foundation Research Institute, Health Policy

Research, 795 El Camino Real, Ames Building, Palo Alto,

CA 94301, USA

e-mail: lufth@pamfri.org; hal.luft@ucsf.edu superior outcomes, thereby fostering innovation improving outcomes and reducing waste.

\section{Introduction}

Economics, in addition to medical research, influences how medical care is delivered, organized, and progresses. Feefor-service (FFS) payment encourages the delivery of services; given the current payment structure, time spent doing procedures is rewarded more highly than time with patients or coordinating care. Some argue these relative payments should be adjusted; shifting that balance, however, will differentially affect various specialties. The concern of this discussion, however, is different: regardless of the relative values for evaluation and management versus procedural services, the prevailing system of feefor-individual-service offers no economic incentives for clinicians to efficiently organize the care delivered by other providers.

This paper discusses the role of payment incentives and how realignment of payment can improve both efficiency and quality at any point in time and, furthermore, reduce the rate of growth in expenditures. The focus here is not on payment levels-providers typically complain fees are too low and payors complain they are too high — but rather on the way that payment is structured. One alternative to feefor-service, global capitation, provides cost-containing incentives because it gives decision makers a fixed budget for all the care their enrollees need. It works well in highly integrated practices but not for independent practitioners without an external entity to coordinate their care. The failures of utilization management in the managed care efforts of the 1990s demonstrated the need for an alternative approach. Episode-based payment is such an 
alternative to FFS on the one hand and global capitation on the other.

Bundling together all the payments associated with an episode of care can better align incentives. Building on Medicare's model for hospital payment, one can define new expanded diagnosis-related groups (EDRGs) including not just hospital costs, but also physician and other costs during the stay and during appropriate preadmission and postdischarge periods. Physicians and hospitals voluntarily forming an entity I will call a care delivery team (CDT) would receive a bundled payment, along with complete flexibility in allocating the funds. The new financial incentives will encourage efficient care for the patient; the episode focus will facilitate measuring patient outcomes. Payment levels, moreover, should be based on the resources used by CDTs achieving superior outcomes, thereby fostering innovation improving outcomes and reducing waste in such care. Medicare has recently begun a demonstration of selected aspects of this concept for certain cardiovascular and joint replacement procedures [2].

Restructuring payment for the ongoing management of chronic illnesses is more complex than the much shorter and more concentrated care associated with an inpatient episode. In brief, for the former I propose a comprehensive approach with monthly chronic illness management payments to accounts associated with primary care physicians. These payments will be risk-adjusted to reflect the chronic conditions of the physicians' patients, and reflect the resources used by those clinicians achieving better than average outcomes for their patients. A major risk pool will pay the CDTs directly for hospital and similar episodes, so the chronic illness management payments need not include those costs. A payment intermediary working on behalf of the primary care physicians will monitor the data and, for those whose patients have lower use of inpatient care but comparable or better outcomes, argue that they should receive higher monthly payments for their superior management of care. The monthly payments serve as the basis for paying not just the primary care physician, but also specialists and other ambulatory care services. The comprehensive approach includes methods to ensure enrollment, the sharing of data, and creation of information useful to both patients and clinicians [5].

The first section of this paper outlines several ways payment can be structured, from the perspectives of how dollars are disbursed by payors and how they are received by providers. The second expands on one of these options, payment from a payor bundled around an inpatient episode, and discusses how funds may be disbursed among the providers involved in the episode. The third section illustrates this concept with data concerning knee arthroplasty procedures. A final section discusses the likely implications of such a payment scheme on efficiency, quality, and longterm cost growth.

\section{Payment and Incentives}

Healthcare providers (meaning both physicians and hospitals) often use the term "reimbursement" for their services, but this is a misnomer. Reimbursement actually refers to situations in which one is paid back for money spent on an official or approved purpose. For example, I trusted the sponsors of this workshop would reimburse my travel expenses upon presentation of the appropriate receipts. They would, however, impose certain constraints, such as reimbursing only up to full coach airfare if I chose to fly first class. On the other hand, they would not pay me the price of a full coach ticket if I purchased a nonrefundable, discounted ticket using a roundabout route. That would be akin to offering me a fixed allowance to cover all travel expenses, thereby shifting the risk and potential benefits to me. A fixed travel allowance would give me incentives to search for cheaper airfares (perhaps freeing up funds for an honorarium), but it would also force me to bear the risk of occasionally absorbing the expenses of nonrefundable tickets for trips that had to be cancelled.

Providers prefer to talk about "reimbursement" for at least two reasons, one historical and the other political. The historical reason is that hospitals used to have contracts with Blue Cross plans (and for a number of years, Medicare) in which they kept track of the proportion of their patients attributed to these payors and at the end of the year were literally reimbursed for that share of their allowable costs. The political reason is that "reimbursement" suggests merely being paid back for expenses incurred-the "language" implies no one is making a profit.

In fact, there is very little true "reimbursement" these days. Hospitals set charges and negotiate rates with private insurers. Payments are often above actual costs incurred; if not, the facility would eventually go bankrupt. Medicare sets the payments it offers hospitals and typically does not care whether these payments cover the costs of its patients-it is like a fixed travel allowance based on the destination of the traveler. Medicare payments to physicians are also set unilaterally, but those payments are based on each unit of service, as if I were allowed a fixed amount for each airline trip, each taxi ride, and each meal. In both instances, there are vigorous arguments over the adequacy of the payments, but little discussion as to the effects of how the payments are structured.

FFS payment to providers is the most common approach to structuring payment. FFS generates some revenue for nearly every service provided; depending on the costs of delivering those services, providers may make or lose 
money. There are some variable costs involved (such as supplies), but medical practice has substantial fixed costs, reflecting rent and depreciation, as well as malpractice insurance, office staff, and operations. The individual physician is usually the residual claimant; his or her income is based on what is left after all the costs are subtracted from the revenue received. High fixed costs mean additional services rendered are likely to be profitable even if on average the revenue received is less than the average cost. In economic terms, this means the marginal (or incremental) revenue exceeds marginal (or incremental) costs associated with one additional service rendered. Incentive effects, or the additional effort one will expend in a given situation, usually reflect such incremental revenues and costs. Thus, FFS creates incentives to provide more services. This is not necessarily problematic; the vast majority of businesses have incentives to offer more of whatever they sell.

Applying these incentives in the context of medical care, however, is problematic because of what is being "sold" or "purchased." Physicians sell specific highly skilled services, hospitals sell operating room time and bed days, pharmacies sell drugs, and device manufacturers sell devices. Most patients, however, want a treatment for their health problem or ongoing care to keep them healthy. In this context, the specific services and items provided by practitioners are simply inputs. While patients often have (or should have) substantial say in decisions about their care, they rarely have the technical expertise to assess the value of specific inputs in achieving a desired outcome.

If a patient needs a surgical procedure, such as for a knee arthroplasty to improve mobility, the patient typically selects the surgeon who decides on the best technical approach. The hospital provides the inpatient services and arranges for the anesthesiologist and the implant. If the system works reasonably well, nothing goes wrong and the procedure is a success. There is nothing, however, in the simple incentives of FFS payment that drives the overall process to become more efficient or produce better quality. For example, the instruments and approach a particular surgeon prefers may be optimal for him or her, but if each surgeon uses a different approach, the operating room team does not have the opportunity to standardize procedures to reduce waste and errors.

A useful, although not perfect, analogy is what happens when undertaking a kitchen remodel. The initial decision as to whether to go forward with the project is based on the homeowner's assessment of the benefits and costs involved. In a kitchen remodel situation, some people decide to serve as their own general contractors, hiring specialists to do specific jobs and coordinating the scheduling. Unless very experienced however, the do-it-yourself general contractor often runs into problems: the floor refinisher wants to be last, but the painter wants to do the baseboards last. General contractors earn their fees both for ensuring seamless coordination and for their expertise in choosing subcontractors who will perform as expected. The subcontractors know failure to perform will affect repeat business, not from the current client, but from the general contractor who needs reliable subcontractors and can offer many jobs in the future.

The problem with the general contractor-subcontractor model is since subcontractors are often working for several general contactors, scheduling cannot be fully integrated and each subcontractor's slightly different work style may not mesh well with others. A few companies, however, are fully integrated; their own crews do all the electrical, plumbing, countertop, and other work. Being able to control everything, they prepare all the materials well in advance in the warehouse and then gut the kitchen and install everything in a week of on-site work. They reduce labor costs for initial steps by having workers move from one "job" to another in the warehouse in the same day. The firm, however, has to bear the risk of having staff on the payroll even when demand slacks off. From the perspective of anyone who has lived through a remodel, the promise of a job completed in a week and on budget is very attractive and this may offset a somewhat higher bid price.

We rarely see either of these contracting arrangements in medical care. Although a hospital may hire nursing and other staff and facilitate access to certain hospital-based physicians, such as radiologists, anesthesiologists, and pathologists, each physician typically acts as an independent provider. One physician may "manage" the clinical aspects of the case, but he or she cannot pay the others to change their schedules, agree on a practice approach, or otherwise coordinate their activities. Various laws and regulations preclude such financial interconnections. Even in the unusual situations in which physicians are employed by the same entity, such as a medical school, a history of specialty independence and prerogatives usually trumps economic integration.

\section{Bundling Payment for Inpatient Care Episodes}

What might a new model of integration for inpatient care look like? The new system would pay for an episode of care, such as a knee arthroplasty or care for a heart attack. These are events a patient can understand, rather than the long list of services, disposables, and devices used in delivering the care. Although I refer to inpatient care, I include similar episodes addressed in an outpatient setting; a procedure involving a 23 -hour stay is not much different to the patient from one that extends to 25 hours. The episode should include closely related preadmission services, 
such as an MRI performed 1 day before a procedure or the emergency room visit ending in the heart attack admission. Likewise, reasonable postdischarge care should be included, including costs due to complications.

One's initial reaction may be that such a system could not work because of various legal, political, and economic risk-related reasons. These are discussed in turn. The legal and regulatory barriers, such as those precluding feesplitting and gainsharing are changeable by new legislation; I will return later to legitimate concerns about the troublesome conflicts of interest that could arise from simply removing existing prohibitions.

The political barriers are less the "big $\mathrm{P}$ " political issues any proposal might face in Congress, but those arising between hospitals and their medical staffs. There is often little trust between hospitals and their affiliated physicians. Although the hospital accounts for the largest share of expenses within most episodes, there is no reason for it to be the recipient of the payment. Instead, the bundled payment could be offered only to a new entity able and willing to provide (or assure the provision of) all the services needed for the episode. Legislation altering existing gainsharing regulations could require that any such new entity establish its own forms of governance acceptable to its members. A hospital could threaten to replace individual physicians, but it will not be able to establish such a new entity on its own. Because most patients seek out physicians and surgeons, not hospitals, this will encourage win-win arrangements. The new governance rules could be written by the participants with an appropriate balance of power between the hospital on the one hand and the participating physicians on the other. Not all physicians on a medical staff will want (or need) to participate in the entity; just enough are required for the new entity to reasonably accept episode-based payments. Avoiding an "all-or-none" situation reduces the power of a single physician to block the deal. CDTs might initially be encouraged under an expansion of Medicare's demonstration authority to offer bundled payments to the voluntarily formed new entities. The amount might be no less than that paid under existing Part $\mathrm{A}$ and $\mathrm{B}$ coverage and be guaranteed not to decline even if there are fee schedule reductions in the future. Teaching hospitals creating CDTs will avoid the cumbersome reporting and documentation requirements of the house staff and attending roles in each patient's care. The new CDT acts as the general contactor accepting a fixed price for the remodel and arranging for and paying the various subcontractors needed to complete the job. A hospital might participate in several separate CDTs, such as for cardiovascular or orthopaedic care. Alternatively, there may just be one CDT with varying arrangements with participating physicians.
The economic risk concerns arise from the nature of a bundled payment to the CDT. Even within a specific diagnosis-related group (DRG), costs vary across patients in the same hospital. Including responsibility for complications within a reasonable period of time substantially increases that variability; ignoring complications, however, eliminates economic incentives to avoid them. The CDT's financial risk can be addressed through reinsurance. The post-discharge responsibility period may be DRG-specific and should maximize the likelihood that readmissions are associated with the CDT's care, rather than the patient's underlying medical problems or poor care in the ambulatory setting. For example, a longer window may be appropriate for admissions of basically healthy people undergoing a joint replacement or delivering a baby, while only a short period would be used for a person with a naturally recurring problem, such as $\mathrm{CHF}$ or emphysema. In some instances a readmission is clearly a complication of care, such as a wound infection with a hospital-specific strain of MRSA. In other instances, the readmission is almost certainly unrelated, such as for a post-discharge gunshot wound. Most readmissions have less clear causes. Across many patients with a given initial reason for admission, however, one can readily estimate the percentage readmitted within a specific period of time for any reason. That percentage times the average cost of those readmissions is the amount that would be added to the payment to the CDT to cover, on average, the cost of readmissions.

Medicare already absorbs some similar episode-based risk with outlier payments for individual hospital admissions that are substantially more costly than the specific DRG payment. An alternative approach can offer more direct incentives for process improvements. The payment to the CDT would include the average cost of a reinsurance policy protecting the CDT from the risk associated with unusually expensive cases. For example, if outlier cases and readmissions currently account for $10 \%$ of all costs associated with a specific DRG, the payment could be increased by a bit over $10 \%$ (to allow for the legitimate costs of the reinsurer) and CDTs could purchase coverage on their own. Reinsurers will have an interest in keeping down such costs and will seek to learn the techniques used by CDTs able to reduce occurrences of complications, or manage them very well once they occur. Reinsurers can go beyond merely selecting CDTs with low complication rates; some will learn best practice techniques from their clients and pass them on to those CDTs wanting to improve their processes. In contrast, the current Medicare system provides neither incentives nor mechanisms to learn and disseminate better techniques.

The notion of bringing together hospitals and physicians in an economically aligned unit is not new; it is part of 
what underlies the concept of "focused factories" for orthopaedic and cardiovascular services [3]. Such specialty hospitals are very attractive in some circles but strongly opposed in others. The interest in them indicates the technical and internal political issues to make them work can be overcome. The opposition arises from two general concerns. The first is, by specializing in certain highly profitable categories of care and by drawing those patients out of other hospitals, they impair the ability of the latter to cross-subsidize patients who are less profitable. The second is they may encourage admissions and procedures that are not necessary.

The first problem is merely a reflection of the current Medicare DRG rates; they are too high for some procedures and too low for many other categories. This is a problem of how those prices are set rather than the underlying concept of bundling; the new severity-adjusted rates implemented by Medicare are designed to address this problem. In a reformed system, prices for each inpatient episode (including all professional and facility costs, plus the appropriate preadmission and postdischarge care) should yield roughly the same profit (or net revenue) margin for each EDRG category. With the need for crosssubsidies eliminated, the first argument against specialized facilities will disappear. Some will object that simply having appropriate pricing of EDRGs, however, does not eliminate the need for cross-subsidies to cover the uninsured. That is a legitimate point if the discussion is focusing only on a specific payor, such as Medicare, but can be addressed by universal coverage for such care, as outlined in my proposal for comprehensive reform [5].

Appropriately setting prices for bundled payment is not trivial, but doing it well can yield several benefits. Medicare currently sets relative DRG weights based largely on the costs nationally of caring for patients in each DRG category with adjustments to reflect local input prices. The final figures are then subject to across-the-board adjustments to meet certain budgetary goals and hence reflect high-level political lobbying. A different approach would use not the national average as the standard, but the costs incurred by those CDTs achieving better than average outcomes for their patients, again adjusting for local wage rates. (The focus here is on relatively proximate outcomes, eg, unexpected complications or achieving anticipated functional levels within 6 months. Long-term outcomes, such as graft patency or device longevity, probably reflect more the choice of intervention than the skill of the CDT.) In contrast to most current attempts to reward quality that focus on either hard endpoints, such as mortality, or adherence to professionally determined processes, the choice of outcome measures should be more patient-oriented. That is, panels should be established with substantial patient input to identify the outcomes patients desire most.
Clinicians will then be able to experiment with new processes to improve outcomes and reduce costs. Total payments, moreover, should not be constrained to meet an overall budget. We should instead rely on the incentives inherent in bundled payments to reduce the inputs used in an episode; other market-based incentives to address the prices for physician time are discussed elsewhere [5].

A commitment to set payments based on what it takes to achieve superior outcomes will increase demand by physicians for collection of better data on outcomes. It will also lead to improving risk adjustment techniques to account for underlying patient comorbidities and understanding what techniques lead to the best outcomes. This will foster innovation in workflow and processes that increase quality. The new system should also explicitly cover the additional costs of new treatments as they are being assessed, much as Medicare offers such coverage with evidence determination. Better outcomes at specific CDTs will result in not just professional and public recognition (thereby attracting referrals) but also in an increased payment level for all, as the new interventions are included in the costs reported by the CDTs achieving superior outcomes.

The problem of demand creation-the classic example being that of Redding Hospital (Redding, CA) and its cardiovascular team who performed procedures on patients who did not need them-must also be addressed [4]. Physicians choosing to be part of a CDT cannot be in the position to self-refer by deciding that a certain patient needs a procedure or admission. Clinicians financially involved with the CDT should not be assessing the need for an admission, but in many instances primary care physicians will not have the technical expertise to make such decisions. Independent specialists doing those assessments can be compensated based on their time and expenses, without rewards for decisions to either intervene or withhold care. Once it has been determined a procedure or admission is warranted, patients will have free choice of CDT teams and physicians within CDTs. The CDT members can certainly decide not to undertake a procedure on a given patient. Physicians not part of a CDT, however, can be involved in the outpatient management of care and in the decisions of whether an admission or a procedure is needed. Primary care physicians and independent medical evaluators outside the CDT may have important insights on the care of patients and the CDT would be able to pay them a fee comparable to their time in the office for consultations.

\section{An Illustration}

To illustrate the potential of bundled payments, we use data for patients undergoing knee arthroplasties during 2003 to 
Table 1. Costs for various services incurred during knee arthroplasty episodes of care commercially insured patients, 2003 to 2004

\begin{tabular}{|c|c|c|c|c|c|c|c|c|c|c|c|}
\hline \multirow[b]{2}{*}{ Services/Fees } & \multicolumn{4}{|c|}{ Costs during inpatient stays (acute only) } & \multicolumn{4}{|c|}{$\begin{array}{l}\text { Cost preadmission and postdischarge } \\
\text { (including rehabilitation stays) }\end{array}$} & \multicolumn{3}{|c|}{ Costs for the whole episode } \\
\hline & $\begin{array}{l}\text { Number } \\
\text { of } \\
\text { patients }\end{array}$ & $\begin{array}{l}\text { Mean } \\
\text { cost for } \\
\text { users }\end{array}$ & $\begin{array}{l}\text { Coefficient } \\
\text { of variation }\end{array}$ & $\begin{array}{l}\text { Mean for } \\
\text { all } \\
\text { patients }\end{array}$ & $\begin{array}{l}\text { Number } \\
\text { of } \\
\text { patients }\end{array}$ & $\begin{array}{l}\text { Mean } \\
\text { cost for } \\
\text { users }\end{array}$ & $\begin{array}{l}\text { Coefficient } \\
\text { of variation }\end{array}$ & $\begin{array}{l}\text { Mean for } \\
\text { all } \\
\text { patients }\end{array}$ & $\begin{array}{l}\text { Mean } \\
\text { cost }\end{array}$ & $\begin{array}{l}\text { Percent } \\
\text { of total }\end{array}$ & $\begin{array}{l}\text { Coefficient } \\
\text { of variation }\end{array}$ \\
\hline Surgeon fees & 4910 & $\$ 2685$ & $56.3 \%$ & $\$ 2685$ & 4273 & $\$ 302$ & $146.1 \%$ & $\$ 263$ & $\$ 2948$ & $13.1 \%$ & $53.4 \%$ \\
\hline $\begin{array}{l}\text { Inpatient facility } \\
\text { costs }\end{array}$ & 4910 & $\$ 13,189$ & $38.6 \%$ & $\$ 13,189$ & 0 & $\$ 0$ & & $\$ 0$ & $\$ 13,189$ & $58.7 \%$ & $38.6 \%$ \\
\hline $\begin{array}{l}\text { Anesthesiologist } \\
\text { fees }\end{array}$ & 4587 & $\$ 699$ & $65.3 \%$ & $\$ 653$ & 480 & $\$ 232$ & $115.9 \%$ & $\$ 23$ & $\$ 676$ & $3 \%$ & $78.4 \%$ \\
\hline $\begin{array}{l}\text { Other } \\
\text { professional } \\
\text { fees }\end{array}$ & 2213 & $\$ 395$ & $133.9 \%$ & $\$ 178$ & 3713 & $\$ 636$ & $154.1 \%$ & $\$ 481$ & $\$ 659$ & $2.9 \%$ & $169 \%$ \\
\hline Ancillary costs & 4496 & $\$ 2065$ & $212.7 \%$ & $\$ 1891$ & 4867 & $\$ 1440$ & $113.4 \%$ & $\$ 1428$ & $\$ 3319$ & $14.8 \%$ & $141.2 \%$ \\
\hline $\begin{array}{l}\text { Rehabilitation } \\
\text { facility costs }\end{array}$ & 0 & $\$ 0$ & & $\$ 0$ & 848 & $\$ 7852$ & $51.9 \%$ & $\$ 1356$ & $\$ 1356$ & $6.0 \%$ & $300.4 \%$ \\
\hline $\begin{array}{l}\text { Outpatient } \\
\text { pharmacy } \\
\text { costs }\end{array}$ & 0 & $\$ 0$ & & $\$ 0$ & 3509 & $\$ 431$ & $151.8 \%$ & $\$ 308$ & $\$ 308$ & $1.4 \%$ & $212.4 \%$ \\
\hline Total costs & 4910 & & & $\$ 18,596$ & 4899 & $\$ 3866$ & $111.3 \%$ & $\$ 3858$ & $\$ 22,454$ & $100 \%$ & $37 \%$ \\
\hline
\end{tabular}

2004 drawn from enrollees in a set of large commercial health plans across the nation. These unpublished data came from the proprietary Ingenix Impact National Managed Care Database which is a large administrative claims database containing inpatient confinement, medical claims, pharmacy claims, and member eligibility information. For this illustration, we used a $10 \%$ random sample (over 800,000 members from numerous national health plans during 2003-04). Of these, 284,446 members had 24 months of continuous commercial (non-Medicare) coverage and 4,910 had knee surgery. (The database is fully deidentified in compliance with HIPAA Privacy Rules.) The database includes some people aged 65 years and over covered primarily through employer-based plans rather than Medicare. The dollar amounts reflect "allowed charges" as paid by the plans and patients. We used the Ingenix Symmetry Episode Grouper 6.5 to create episodes of care, but focus only on the services during and proximate to a hospital admission. Patients were selected if they had a knee arthroplasty (CPT-4 code 27447) with a physician identified as an orthopaedic surgeon. We excluded a small number (95) of persons with more than one knee arthroplasty in a year because we could not determine whether the code reflected complications of the index knee operation rather than surgery on the other knee. We only included patients grouped into ETG 0721 (joint degeneration, localized, with surgery-knee and lower leg) for the knee arthroplasty group. We examined costs by various types of service and those delivered either during the inpatient stay or in the period before or after admission.
The mean episode cost across all 4910 patients was $\$ 22,454$, with an average of $\$ 18,596$ incurred during the inpatient stay and the remainder during preadmission and postdischarge periods, including rehabilitation stays. Not all patients incur charges in all categories, and some charges are seen for only a small fraction of all patients (Table 1). The total cost is rather stable, with a coefficient of variation of $37 \%$, indicating the standard deviation is a little more than $1 / 3$ of the mean. Nearly all episodes include charges for hospital, anesthesiologist, and ancillary costs, along with surgeon fees. Hospital costs averaged $\$ 13,189$, nearly $60 \%$ of the total, whereas surgeon fees during the episode averaged $\$ 2948$, or about $13 \%$ of the total. Total ancillary fees exceed surgeon fees but with a coefficient of variation nearly three times as large.

Without detailed clinical information, it is impossible to know whether the variability in resource use across patient episodes is due simply to underlying patient factors. The widely documented variability in resource use across geographic areas and individual medical centers without any clear evidence in similar differences in patient risk, however, suggests patient factors may not fully account for what we see. (See, for example, discussions by Jon Lurie [6] in this issue.) There is little evidence that areas or centers with consistently higher resource use achieve better patient outcomes. In the absence of compelling new information, we should modify the usual baseline in which it is assumed (1) most variation is due to patient risk factors, and (2) increased resource use controlling for patient risk factors is indicative of higher quality. Instead, our 
baseline should be (1) the extent of patient-specific need must be measured with better clinical data, and (2) outcomes should be continually assessed to determine what mixes of inputs and services are best for specific patient problems.

The potential for creative resource allocation is apparent; a relatively small reduction in hospital costs could allow substantially increased compensation for other members of a CDT (Table 1). Such a saving in hospital costs, however, is likely to require adaptations by nursing staff, anesthesiologists, and others involved in the episode. These solutions cannot be easily imposed by external bodies but are likely to be achieved voluntarily by the new CDTs with the flexibility to allocate funds. Ancillary costs exceed surgeon fees but are usually ordered by the surgeons; they could also be a source of savings. CDTs choosing to share some of their savings with price-sensitive patients may increase their volume, and hence total revenue, at the expense of other, less efficient CDTs.

\section{Discussion}

There is much concern about how much we spend on medical care and how uneven is the quality of care we get, but little attention has been paid to the implications of how we pay medical care providers. The current system of fees for individual services is at the root of both our cost and quality problems. The incentives implicit in a bundled payment covering all the relevant providers involved in an inpatient episode can encourage far more efficiency. If designed appropriately, such a payment approach can also facilitate learning what works best in practice and then changing processes to improve quality. In the long run, this new focus will impact the translation of new research into practice, emphasizing increased efficiency and improved value.

The conceptual arguments in favor of episode-based payments are clear; the details and transition are more challenging. Episode-based payments and bundling are far more complex in the outpatient setting for numerous reasons, so this discussion has focused on inpatient (and similarly intensive and short duration) care. It is easy for payors to "bundle payment" but much harder for independent practitioners and a hospital to figure out how to share risk, rewards, and responsibilities among themselves. With the fear of malpractice in the background, few providers will leap at the opportunity to redesign care in ways that may appear to be "doing less," so a reform of the liability system must be considered. For a few categories of conditions, such as acute myocardial infarction, there is a reasonable consensus on outcomes, such as death within 30 days, that are reasonably well measured. For most patients, such as those having elective surgery, procedureassociated death should be a rare or never event. From the patient perspective, outcomes matter most; not only should each professional do his or her job excellently, but the overall processes of the team members involved in the care must facilitate "hand-offs," optimal choices of treatments, and continuous improvement. Developing agreed-upon outcome measures incorporating both professional opinion on what can be measured and patient values on what is important will take time and resources. The model proposed here focuses on quality measures across groups of similar patients, with ample opportunity for increased risk adjustment as we learn about relevant risk factors. Without having to score each case as a "success or failure" one can use robust statistical approaches that account for random variation while seeking to detect consistently better than expected performance. None of these issues are trivial, but the best way to address them is to begin with volunteering organizations, feasible target conditions, and demonstrations.

Episode-based payment creates incentives for physicians to focus on the best ways to manage resources during an episode of illness or care; the CDT creates the economic unit in which such incentives can be turned into action. (The issues are somewhat more complicated in managing an ongoing chronic illness involving a wide range of providers who may not normally work together and often requiring patient cooperation in adherence to various treatment regimens. Thus, different incentives and structures are needed for a relatively brief episode of care focused on an inpatient stay and for the ongoing management of illness. The latter are discussed in much more detail in my comprehensive proposal [5].)

Episode-based payment allows the appropriate compensation for the time professionals need to effectively coordinate services. Payment approaches within the new CDT may vary widely. Surgeons may still be paid per procedure and anesthesiologists by the time in the operating room, while the hospitalists involved in the postoperative care may be paid by the shift. The CDT may hire patient navigators and technical support personnel to efficiently coordinate all the members of the team or optimize the use of various implants and instrumentation. Payment rates, moreover, might be adjusted by workload to better use scarce resources, such as encouraging the use of operating room time during weekends.

The bundled payment that includes not just professional fees, moreover, creates incentives to redesign workflow within the inpatient stay and at other times during the episode. This can range from relatively simple things, such as standard preoperative protocols and drug regimens, to agreeing on a smaller number of implants or a preferred formulary. While one cannot assume all imaging 
performed by referring clinicians meets the CDT's standards, many may be perfectly adequate. CDTs might even train referring clinicians in the techniques needed to reduce the preadmission workup process - a savings not only in resources but also in time and risk to the patient.

Episode-based payment must be designed to avoid incentives to skimp on care to increase profits to the CDT. Quality concerns, however, are not particularly associated with episode-based payment, as illustrated by the tainted medications derived from Chinese manufacturers [1]. There are always incentives for producers to skimp on quality if it is not well monitored and if the losses due to discovery are small relative to the gains for the badly behaving producer. If we no longer assume more is necessarily better, then paying for episodes means attention will shift to the outcomes of episodes, a measure about which patients care, rather than to the processes and inputs, about which they have little technical knowledge. Using independent medical evaluators outside the CDTs to assess whether surgery is needed offers a useful approach. The independent medical evaluators may also recommend which CDTs have the best outcomes based on both riskadjusted outcome measures and reports gathered from the patients seen.

Turning our focus to outcomes will initially be a challenge. Few meaningful measures are routinely captured in administrative data other than events that should rarely occur, such as death or serious complications. In most instances, medical and surgical interventions are not intended to postpone death but to enhance function and the quality of life. These often require direct assessment by the patients themselves. Such assessments should be viewed as evaluating not the specific professionals involved but the ability of the whole team to achieve the outcomes desired by the patient and should recognize patients may differ in what they think is important. Automobiles are not evaluated in the market solely based on "hard end points," such as their crashworthiness and miles per gallon; customers have varying preferences for style, reliability, and performance. Highly unsafe cars should be kept off the road, but there is room for a great deal of individuality in many other aspects. Just as Road and Track and Consumer Reports may rate the same cars differently, patients should be able to choose among assessment schemes that match their own preferences for certainty, performance, and processes.

Most healthcare professionals simply want to achieve the best outcomes for their patients, but the fear of malpractice liability may lead some to perform unnecessary tests and to be uneasy about the prospect of experimenting with new ways of organizing and delivering care. Episodebased payments to CDTs should be combined with reform of the malpractice liability system that benefits patients, providers, and even attorneys.
In brief, if an injury occurs due to an error in the care of a patient, there should be a quick resolution with an apology by members of a CDT and compensation paid to the patient. Negligence will not need to be proven; the payment is set through an administrative determination of a preventable adverse event and the extent of the injury sustained. (Medical care often involves inherent risks; no compensation would be provided for unfortunate outcomes without evidence of an error.) Plaintiffs' attorneys would simply collect and document the data supporting the claim and probably be paid by the hour. Most CDTs would selfinsure for these common and relatively small claims. A series of similar claims paid by the CDT without evidence it attempted to improve its processes, however, could result in a second-tier suit proving "corporate negligence" with a much larger potential award. That award would be shared with those patients (and their attorneys) involved in the earlier claims who implicitly granted access to their data. In this reformed system, patients would receive just compensation for errors and CDTs would have incentives to learn from previous mistakes, two legitimate arguments of those defending the current system. Physicians would not be charged with negligence for what was merely an error, even if an avoidable one, and far less would be spent on litigation, legitimate arguments of those opposing the current system.

Episode-based payment creates immediate economic incentives for teams to use resources more efficiently. More important for the long term, it changes the incentives for biomedical innovators. The current incentive is to develop new medications, devices, and procedures with some promise of improved quality of care, irrespective of cost. For some innovations, their attractiveness is even enhanced by additional professional fees associated with their use; if physicians can earn an additional fee for the procedure accompanying the biologic or device, they effectively become part of the marketing team of the manufacturer. In contrast, episode-based payment will lead clinicians to consider all costs in relation to the enhancement in quality. The most attractive innovations will be those improving quality and reducing cost, even if this means reducing what are now billable services. Other innovations may have no measurable effect on quality but will reduce costs; for instance, new technologies may allow lower-skilled workers to substitute for some of the tasks highly paid clinicians now do. With the cost of the device bundled into the payment, surgeons will demand evidence that "innovative" devices truly are better. Device manufacturers will find, unless they have breakthrough technology with demonstrably better results, they will be financially better off lowering the costs of tried-and-true devices and gaining market share. The new incentives will, therefore, alter the mix of technological innovations 
entering the healthcare system, slowing the long-term rate of growth in expenditures.

Reform of the healthcare system needs to go beyond strategies that simply provide more people with insurance coverage that fosters inefficiency, poor quality through disincentives for coordination, and mindless cost-containment efforts through fee reductions. Instead, reforms should focus on improving the payment system to appropriately align incentives and facilitate clinicians in being the best professionals they can be.

The charge for the Association of Bone and Joint Surgeons/C.T. Brighton Workshop is to discuss where we are now, where we need to go, and how to get there. Nearly all observers of the US healthcare system agree it fails to cover a substantial fraction of the population and yet is more expensive than all other systems in the developed world. Most agree, while the quality of care in some instances is outstanding, it is not as good as it can be. The rate of growth in expenditures is unsustainable in the long run and something needs to be done to slow this. Explicit rationing of services is politically unacceptable. Reductions in provider payments yield short-term cost containment, but many believe the current system merely adapts by increasing the use of services and procedures, further fueling expenditure growth while devaluing physician effort and driving many clinicians out of practice.

Fragmented payment to individual providers for their own services is one of the causes of this sorry situation. A solution for inpatient and similar care that can work in the US environment is to bundle payments around an episode of care. This new payment will be made to a CDT composed of physicians, hospitals, and other professionals who will provide the necessary services. They will decide how to pay themselves and organize care to both increase quality and efficiency. The CDTs will demand better information on patient outcomes and learn from other CDTs how to constantly improve. Biomedical innovation will shift from being cost increasing to being value enhancing.

The changes needed to move to bundled payments are within reach. Some existing federal and state legislation will need to be modified to allow the creation of CDTs. Bundled payment could be done without reform of liability laws, but enacting the type of malpractice reform suggested above can help reassure physicians that well-intended innovation will not unduly expose them to liability claims. The underlying data to begin the implementation process are available, but incentives are needed to pool the data from Medicare and other payors. Medicare has begun some relevant demonstration projects and these should be expanded. Creating the new teams will require substantial effort, so there should be clear guidance from national leaders that the payment system will be changing and incentives provided for voluntary early adopters. For example, new CDTs might be guaranteed payments no less than their present Medicare Part A and B payments with exemptions from any future fee reductions, but the ability for their payments to be adjusted upwards along with everyone else. Academic medical centers might avoid their troublesome service-by-service documentation requirements if they transformed their practice plans into CDTs.

A shift to episode-based payment will require a different way of thinking about how care is provided and professionals are paid. It will require the development of functioning teams that replace totally independent economic entities. It offers, however, an economic basis for creative approaches to medical care delivery that are based on what works, yet adaptive to patient needs and scientific advances. Not all the details of such a fundamental change can be worked out in advance, but we cannot wait for the perfect solution to our rising healthcare costs.

Acknowledgments I thank Laura J. Eaton, MD, MPH, for her help with the data analysis included in this paper.

Open Access This article is distributed under the terms of the Creative Commons Attribution Noncommercial License which permits any noncommercial use, distribution, and reproduction in any medium, provided the original author(s) and source are credited.

\section{References}

1. Barboza D. China orders new oversight of heparin, with tainted batches tied to U.S. deaths. New York Times. March 22, 2008. Available at: http://www.nytimes.com/2008/03/22/world/asia/22 heparin.html. Accessed November 29, 2008.

2. Centers for Medicare and Medicaid Services. CMS announces sites for demonstration to encourage greater collaboration and improve quality using bundled hospital payment, January 7, 2009. Available at: http://www.cms.hhs.gov/apps/media/press/release.asp? Counter $=3394 \&$ intNumPerPage $=10 \&$ checkDate $=\&$ checkKey $=\&$ srchType $=1 \&$ numDays $=3500 \&$ srchOpt $=0 \&$ srchData $=\&$ keyword Type $=$ All $\&$ chkNewsType $=1 \% 2 \mathrm{C}+2 \% 2 \mathrm{C}+3 \% 2 \mathrm{C}+4 \% 2 \mathrm{C}+5 \&$ int Page $=\&$ showAll $=\& p$ Year $=\& y e a r=\&$ desc $=$ false $\&$ cboOrder $=$ date . Accessed May 6, 2009.

3. Herzlinger R. Market Driven Health Care: Who Wins, Who Loses in the Transformation of America's Largest Service Industry. New York, NY: Basic Books; 1999.

4. Lenzer J. Healthcare group agrees $\$ 500 \mathrm{~m}$ settlement for unnecessary surgery. BMJ. 2006;333:59.

5. Luft HS. Total Cure: The Antidote to the Health Care Crisis. Cambridge, MA: Harvard University Press; 2008.

6. Lurie JD, Bell JE, Weinstein J. What rate of utilization is appropriate in musculoskeletal care? Clin Orthop Relat Res. 2009 May 19. [ePub ahead of print]. 